\title{
Lifestyle factors associated with obesity in a cohort of males in the central province of Sri Lanka: a cross-sectional descriptive study
}

N. W. I. A. Jayawardana', W. A. T. A. Jayalath², W. M. T. Madhujith³, U. Ralapanawa², R. S. Jayasekera4, S. A. S. B. Alagiyawanna ${ }^{2}$ A. M. K. R. Bandara ${ }^{5}$ and N. S. Kalupahana ${ }^{6^{*}}$

\begin{abstract}
Background: Obesity has become a global epidemic. The prevalence of obesity has also increased in the South Asian region in the last decade. However, dietary and lifestyle factors associated with obesity in Sri Lankan adults are unclear. The objective of the current study was to investigate the association of dietary and lifestyle patterns with overweight and obesity in a cohort of males from the Central Province of Sri Lanka.

Methods: A total of 2469 males aged between 16 and 72 years $(\bar{x}=31)$ were included in the study. The sample comprised individuals who presented for a routine medical examination at the National Transport Medical Institute, Kandy, Sri Lanka. The Body Mass Index (BMI) cutoff values for Asians were used to categorize the participants into four groups as underweight, normal weight, overweight or obese. The data on dietary and lifestyle patterns such as level of physical activity, smoking, alcohol consumption, sleeping hours and other socio demographic data were obtained using validated self-administered questionnaires. Multinomial logistic regression model was fitted to assess the associations of individual lifestyle patterns with overweight and obesity.

Results: The mean BMI of the study group was $22.7 \mathrm{~kg} \mathrm{~m}^{-2}$ and prevalence rates of overweight and obesity were 31.8 and $12.3 \%$, respectively. Mean waist circumference of the participants was $78.6 \mathrm{~cm}$ with $17.1 \%$ of them being centrally obese. After adjusting for potential confounders, weight status was associated with older age $(P<0.0001)$, ethnicity $(P=0.0033)$ and higher income $(P=0.0006)$. While higher physical activity showed a trend for being associated with lower odds of being obese (odds ratio: 0.898 - confidence interval: 0.744-1.084), alcohol intake, consumption of fruits, level of education, sleeping hours, smoking, consumption of fish, meat, dairy, sweets or fried snacks were not significantly associated with the weight status.

Conclusion: The high prevalence rates of overweight and obesity in working-age males is a threatening sign for Sri Lanka. Since the prevalence rate is higher in certain ethnic groups and higher-income groups, targeted interventions for these groups may be necessary.
\end{abstract}

Keywords: Overweight, Obesity, Lifestyle factors, Physical activity, Diet, Sri Lanka, South Asia

\footnotetext{
* Correspondence: skalupahana@pdn.ac.lk

${ }^{6}$ Department of Physiology, Faculty of Medicine, University of Peradeniya,

Peradeniya, Sri Lanka

Full list of author information is available at the end of the article
} 


\section{Background}

Obesity has traditionally been considered as a health problem of affluent countries [1], while under nutrition and infectious diseases were considered to be major problems in the developing world [2]. However, with the recent escalation of obesity rates worldwide [3], developing countries, particularly ones in South Asia, are facing a double burden of over and undernutrition [4]. Sri Lanka is a country in South Asia, with a population of more than 20 million. It recently gained the lower-middle-income status. According to the World Health Organization (WHO) non-communicable diseases country profiles, the prevalence rates of overweight $\left(B M I \geq 25 \mathrm{~kg} / \mathrm{m}^{2}\right)$ and obesity $\left(\mathrm{BMI} \geq 30 \mathrm{~kg} / \mathrm{m}^{2}\right)$ among Sri Lankans were $5.1 \%$ (2.6\% males and $7.4 \%$ females) and $21.9 \%$ (16.7\% males and $26.8 \%$ females) respectively in year 2008 [5].

There is a large body of evidence suggesting that the epidemic of overweight and obesity is related to the lifestyle factors of individuals [6-8]. Over time, the relationship between lifestyle patterns and obesity has been extensively studied in western populations, nevertheless, little interest was shown to investigate the risk factors associated with overweight and obesity in South Asia. In fact, limited information is available on different lifestyle patterns associated with overweight and obesity in Sri Lankan adults. Thus, we have been referring to the lifestyle recommendations made for western populations, which is inappropriate since the dietary habits and physical activity patterns of Sri Lankans are different from that of western counterparts [9]. The aim of the present study was to determine the prevalence of overweight and obesity and the underlying lifestyle factors associated with those conditions among a cohort of males in the central Province of Sri Lanka.

\section{Methods}

\section{Research design and population}

A cross-sectional descriptive study was conducted with 2469 adult males aged between 16 and 72 years $(\bar{x}=31)$, who presented themselves for a routine medical evaluation done every 4 years at the National Transport Medical Institute, Kandy, Sri Lanka from January 2013 to February 2014. All males who participated in the medical evaluation were considered for the study sample except for the males previously diagnosed with heart diseases, diabetes, hypertension or other chronic illnesses. Institutional review board approval was obtained from the ethics review committee of the Faculty of Medicine, University of Peradeniya, Sri Lanka. (2015/EC/13). All participants in the study signed an informed consent form.

\section{Data collection}

\section{Anthropometric measurements}

Height, weight and waist circumference (WC) were measured according to the WHO guidelines [10]. The measurements of height to the nearest millimeter and weight to the nearest $100 \mathrm{~g}$ were taken using a stadiometer with a scale (Healthweigh Mechanical Physician Scale (RL-MPS), Goldbell Weigh-System, Singapore). The waist circumference measurement (midpoint between the lowest palpable rib and the superior border of the iliac crest in the mid axillary line at the end of normal expiration) was taken using a non-elastic measuring tape to the nearest millimeter.

The following formula was used to calculate the body mass index (BMI):

$$
\operatorname{BMI}\left(\mathrm{kg} / \mathrm{m}^{2}\right)=\frac{\text { Weight }(\mathrm{kg})}{\operatorname{Height}\left(\mathrm{m}^{2}\right)}
$$

BMI cutoff values for Asians defined by WHO [11] were used in the present study to categorize the participants as underweight (BMI $<18.5 \mathrm{~kg} / \mathrm{m}^{2}$ ), normal (BMI $\left.18.5-22.9 \mathrm{~kg} / \mathrm{m}^{2}\right)$, overweight $\left(23-27.5 \mathrm{~kg} / \mathrm{m}^{2}\right.$ and obese $\left(>27.5 \mathrm{~kg} / \mathrm{m}^{2}\right)$ and named this categorical variable as weight status. Further, central obesity was defined as WC $>90 \mathrm{~cm}$ for males according to Asian cut-off values [12].

\section{Dietary data}

A validated, self-administered food frequency questionnaire was used to collect dietary data, where data reflecting the consumption levels of meat, fish, dairy products, fried and salty snacks, sweets and fruits by the participants over the past 6 months (from June 2012 to August 2014) were collected. For the purpose, the participants were asked to provide answers based on their general food consumption patterns and frequency of different foods per week for a period of 6 months.

\section{Assessment of the level of physical activity, smoking, alcohol consumption, sleep and socio-demographic data}

Physical activity level was assessed using the short version of the International Physical Activity Questionnaire (IPAQ) [13]. Physical activity levels were categorized based on the number of minutes they had participated in moderate-intensity and/or vigorous-intensity activity during the week. When a person participated in less than 150 min of moderate-intensity physical activity or less than 75 min of vigorous-intensity activity per week, it was considered as low physical activity level whereas participation in 150-300 min of moderate-intensity activity or 75-150 min of vigorous-intensity physical activity per week was considered as medium physical activity level. A person was considered to have a high physical activity level when that person participated $>300$ min of 
moderate-intensity physical activity per week [13-15]. Smoking, alcohol consumption and duration of sleep were assessed using a self-administered questionnaire.

Data on age, gender, ethnicity, level of education and household income were collected using an intervieweradministered questionnaire. Educational level was classified into four categories: no formal education to primary education (grade 1-5), secondary education-1 (grade 611) secondary education-2 (grade 12-13) and tertiary education (under-/post-graduate) [adopted and modified from 16]. Monthly household income was categorized as follows: Sri Lankan rupees $($ LKR) $<6999$, LKR 7000-12 999, LKR 13 000-24 999, LKR 25 000-49 999 and > LKR 50000 [16]. (1 USD = 145 LKR).

Smoking score was developed based on the number of cigarettes smoked per day by each individual. When a person smoked 1-10 cigarettes per day, that person was considered as a moderate smoker while $>10$ cigarettes per day, a heavy smoker [17]. The number of hours slept per day by each individual was used to construct the sleeping score. When a person slept for $<6 \mathrm{~h}$ per day that was considered as a low sleeping score. Medium sleeping score was considered when a person slept for $7-8 \mathrm{~h}$ per day while $>8 \mathrm{~h}$ of sleep per day was considered a high sleeping score [18].

\section{Statistical analysis}

Data were analyzed using SAS 9.3 (SAS Institute Inc., Cary, NC). Descriptive statistics such as mean and Standard Deviation (SD) were computed for continuous variables and frequencies and percentages were computed for categorical variables. Since the dependent variable, weight status, has four categories, we performed multinomial logistic regression [19] to estimate odds ratios (ORs), considering normal weight as the reference category. Hence, the associations of dietary variables and other lifestyle variables on weight status were assessed using a single model. In this model, independent variables, alcohol intake, sleeping hours, smoking, consumption of fruits, fish, meat, dairy, sweets and fried snacks considered as numerical variables and entered into the model as frequency per week. Further, age was considered a numerical variable and other independent variables (education, income category and ethnicity) were entered into the model as categorical variables. Effect of each variable was tested after adjusting for other confounding variables. A significant level of 0.05 was considered.

\section{Results}

Baseline characteristics of the study variables are summarized in Table 1 and demographic characteristics of the study sample are summarized in Table 2 . Mean age of the study sample was 31 years with a mean BMI of $22.7 \mathrm{~kg} / \mathrm{m}^{2}$. Mean WC was $78.6 \mathrm{~cm}$ and $17.1 \%$ of the study sample were centrally obese (Table 3 ).
Table 1 Baseline characteristics of the study sample

\begin{tabular}{llc}
\hline Characteristic & Mean & $\pm \mathrm{SD}$ \\
\hline Age (years) & 31 & 10.27 \\
Height $(\mathrm{m})$ & 1.65 & 0.059 \\
Weight $(\mathrm{kg})$ & 62.54 & 11.96 \\
BMI $\left(\mathrm{kg} / \mathrm{m}^{2}\right)$ & 22.71 & 4.22 \\
WC $(\mathrm{cm})$ & 78.67 & 11.33 \\
\hline
\end{tabular}

$n=2466 ; B M I$ body mass index, SD standard deviation, WC waist circumference

Table 2 Socio-demographic characteristics of the study group

\begin{tabular}{|c|c|c|}
\hline & Number & $\%$ of participants \\
\hline \multicolumn{3}{|l|}{ Age category $(n=2466)$} \\
\hline$<30$ & 396 & 16.06 \\
\hline $31-40$ & 816 & 33.09 \\
\hline $41-50$ & 717 & 29.08 \\
\hline $51-60$ & 415 & 16.83 \\
\hline$>60$ & 122 & 4.95 \\
\hline \multicolumn{3}{|l|}{ Ethnicity $(n=2461)$} \\
\hline Sinhala & 2065 & 83.91 \\
\hline Tamil & 191 & 7.76 \\
\hline Moor & 201 & 8.17 \\
\hline Other & 04 & 0.16 \\
\hline \multicolumn{3}{|l|}{ Level of education ( $n=2342$ ) } \\
\hline No education - grade 5 & 17 & 0.73 \\
\hline Grade 6 - grade 11 & 353 & 15.07 \\
\hline Ordinary level passed & 1229 & 52.48 \\
\hline Advanced level passed & 679 & 28.99 \\
\hline Graduate/postgraduate & 64 & 2.73 \\
\hline \multicolumn{3}{|c|}{ Monthly household income $(n=1830)$} \\
\hline$\leq$ LKR 6999 & 31 & 1.69 \\
\hline LKR 7000-12,999 & 151 & 8.25 \\
\hline LKR 13,000-24,999 & 832 & 45.46 \\
\hline LKR 25,000-49,999 & 720 & 39.34 \\
\hline$\geq \operatorname{LKR} 50,000$ & 96 & 5.25 \\
\hline \multicolumn{3}{|l|}{ Smoking score $(n=2466)$} \\
\hline Non smoker & 2112 & 85.64 \\
\hline$<10$ cigarettes per day & 349 & 14.15 \\
\hline$>10$ cigarettes per day & 5 & 0.20 \\
\hline \multicolumn{3}{|c|}{ Alcohol consumption $(n=2464)$} \\
\hline Non alcoholic & 1902 & 77.19 \\
\hline Alcoholic & 554 & 22.48 \\
\hline \multicolumn{3}{|l|}{ Sleeping score $(n=2466)$} \\
\hline$\leq 6 \mathrm{~h} /$ day & 93 & 3.77 \\
\hline $7-8$ h/day & 1939 & 78.63 \\
\hline$>8$ h/day & 394 & 15.98 \\
\hline \multicolumn{3}{|c|}{ Physical activity level $(n=2466)$} \\
\hline Low & 465 & 18.86 \\
\hline Medium & 345 & 13.99 \\
\hline High & 1590 & 64.48 \\
\hline
\end{tabular}

LKR-Sri Lankan Rupees (1USD = 145 LKR) 
Table 3 Waist circumference levels (95\% Confidence interval (CI)) of the study population

\begin{tabular}{llll}
\hline Waist circumference level & $\%(\mathrm{Cl})$ & Risk level & Central obesity \\
\hline$<90 \mathrm{~cm}$ & $82.89(81.48,84.39)$ & No risk & None \\
$90-102 \mathrm{~cm}$ & $14.4(12.96,15.87)$ & High risk of developing NCDs & Present \\
$>102 \mathrm{~cm}$ & $2.72(1.30,4.21)$ & Greater risk of developing NCDs & Present \\
\hline
\end{tabular}

Within the study sample, $22.48 \%$ consumed alcohol and $14.35 \%$ were smokers where $14.15 \%$ of them were moderate smokers while only $0.2 \%$ of them were heavy smokers. Majority of the participants in the study sample (78.63\%) had 7-8 h of sleep per day. Self-reported physical activity levels revealed that $64.48 \%$ of the study sample had high a physical activity level of $300 \mathrm{~min}$ of moderate-intensity physical activity per week. Nearly 99\% of the participants in the study sample had received school education, while nearly $40 \%$ of the sample had a fairly good income (approx. US\$ 250-450).

Self-reported frequency of meat, fish, dairy, fried snacks, sweets and fruits consumption of all participants in the study sample is shown in the Fig. 1. Results revealed that, $28 \%$ of the participants in the study sample consumed fruits at least seven times per week whereas only $14.5 \%$ of the study sample consumed more than one portion of fruits per day (all together $42.5 \%$ consumed one or more fruit per day-Fig. 1).

\section{Prevalence of overweight and obesity}

The prevalence rates of overweight and obesity were 31.8 and $12.3 \%$, respectively (Table 4 ). Overweight and obesity were higher among males aged between 41 and 50 years compared to the younger age groups. According to the results, when age increased by 10 years, the males were more likely to be overweight (OR: 1.449) or obese
(OR: 1.647) than being normal weight persons. The oldest age group (age $>60$ years) had the highest levels of overweight (43.44\%) and obesity $(22.95 \%)$. The results also showed that, Moors were more prone to be overweight (OR: 1.684) or obese (OR: 2.608) than Sinhalese. Moreover, the odds of being overweight was higher for income groups 4 (OR: 2.742) and 5 (OR: 3.305) compared to income group 1 (Table 5). Table 6 gives the odds ratios and confidence interval of significant variables for overweight and obese compared to normal weight group. Among the variables studied, age, ethnicity and family income were significantly $(P<0.05)$ associated with weight status. When the level of physical activity was considered, higher physical activity showed a trend for being associated with lower odds of being obese (odds ratio: 0.898 - confidence interval: 0.7441.084) (Table 6). Alcohol intake $(P=0.058)$, level of education $(P=0.1246)$, sleeping hours $(P=0.9847)$, smoking $(P=0.5872)$, consumption of fish $(P=0.6042)$, meat $(P=0.7729)$, dairy $(P=0.6190)$, fruits $(P=0.1803)$, sweets $(P=0.4472)$ and fried snacks $(P=0.8792)$ were not significantly associated with weight status.

\section{Discussion}

Obesity is an emerging problem in the South Asian region. However, the lifestyle factors associated with obesity in this region are not well studied. This knowledge is

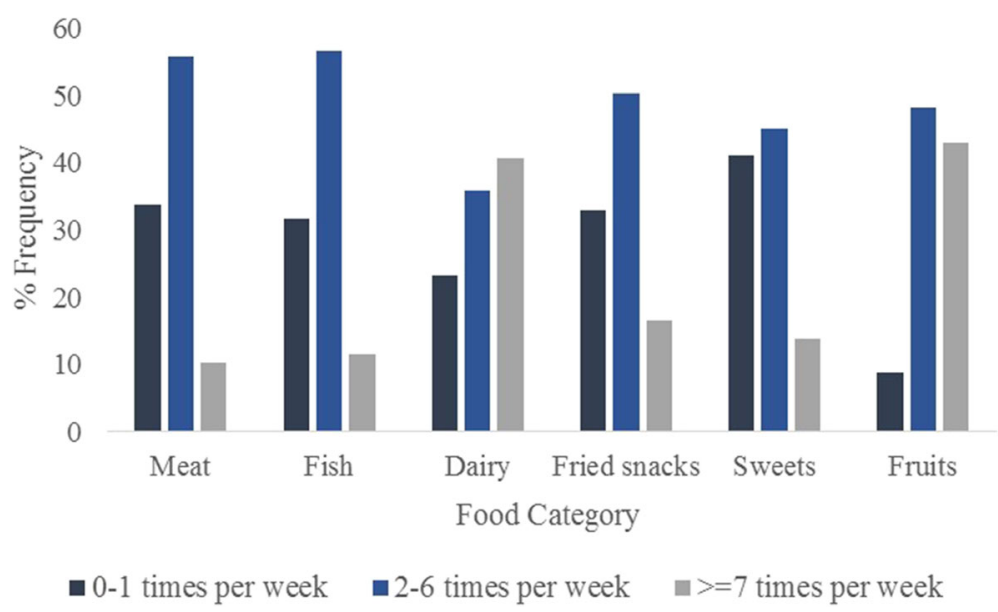

Fig. 1 Frequency of different food consumption of the study sample. Intake of different foods were assessed using a self-administered food frequency questionnaire 
Table 4 Prevalence $(95 \%$ Cl) of overweight and obesity according to BMl cut-offs for Asians

\begin{tabular}{lcl}
\hline & Percent & $\mathrm{Cl}$ \\
\hline Overweight & 31.8 & $29.68,33.93$ \\
Obese & 12.3 & $10.22,14.46$ \\
\hline Cl confidence interval & &
\end{tabular}

required to design tailor-made interventions to prevent obesity. Thus, the purpose of this study was to identify lifestyle factors associated with obesity in a cohort of males in the Central Province of Sri Lanka. The prevalence rates of overweight and obesity in this group were 31.8 and $12.3 \%$, respectively, with the prevalence rate of central obesity being $17.1 \%$.

In this study, the mean BMI and WC reported were $22.7 \mathrm{~kg} / \mathrm{m}^{2}$ and $78.67 \mathrm{~cm}$, respectively. Similar mean BMI $\left(21.1 \mathrm{~kg} / \mathrm{m}^{2}\right)$ and WC $(78.0 \mathrm{~cm})$ for males were reported in a national study conducted by Katulanda et al. [20] which was carried out in seven provinces of Sri Lanka in 2010. Fairly comparable BMI and WC values were observed among few Asian male populations: India

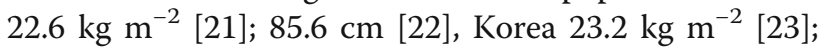

Table 5 Prevalence (95\% Cl) of overweight and obesity among males by age, ethnicity, income category and education level

\begin{tabular}{|c|c|c|}
\hline Variable & Overweight \% (Cl) & Obese \% (Cl) \\
\hline \multicolumn{3}{|l|}{ Age category $(n=2466)$} \\
\hline$<30$ & $16.16(11.11,21.48)$ & $7.58(2.53,12.89)$ \\
\hline $31-40$ & $23.90(20.34,27.59)$ & $9.07(5.51,12.76)$ \\
\hline $41-50$ & $42.12(38.35,46.16)$ & $14.23(10.46,18.27)$ \\
\hline $51-60$ & $40.96(35.90,46.15)$ & $16.87(11.81,22.05)$ \\
\hline$>60$ & $43.44(34.43,53.18)$ & $22.95(13.93,32.69)$ \\
\hline \multicolumn{3}{|l|}{ Ethnicity $(n=2461)$} \\
\hline Sinhalese & $31.67(29.39,34.02)$ & $11.91(9.64,14.26)$ \\
\hline Tamil & $32.98(25.65,40.60)$ & $12.04(4.71,19.66)$ \\
\hline Moor & $32.84(25.87,40.43)$ & $15.92(8.96,23.52)$ \\
\hline \multicolumn{3}{|l|}{ Income category $(n=1830)$} \\
\hline$\leq$ LKR 6999 & $22.58(6.45,41.11)$ & $9.68(0.00,28.20)$ \\
\hline LKR 7000-12,999 & $28.48(20.53,37.13)$ & $13.91(5.96,22.56)$ \\
\hline LKR 13,000-24,999 & $34.13(30.53,37.80)$ & $9.86(6.25,13.52)$ \\
\hline LKR 25,000-49,999 & $39.17(35.28,43.09)$ & $16.11(12.22,20.03)$ \\
\hline$\geq \operatorname{LKR} 50,000$ & $43.75(33.33,54.22)$ & $20.83(10.42,31.31)$ \\
\hline \multicolumn{3}{|l|}{ Education level $(n=2342)$} \\
\hline No education - grade 5 & $23.53(5.88,50.64)$ & $11.76(0.00,38.87)$ \\
\hline Grade 6 - grade 11 & $30.59(25.21,36.21)$ & $11.90(6.52,17.51)$ \\
\hline Ordinary level passed & $33.41(30.48,36.49)$ & $11.65(8.72,14.73)$ \\
\hline Advanced level passed & $30.97(26.99,35.00)$ & $14.75(10.77,18.78)$ \\
\hline Graduate/postgraduate & $31.25(20.31,45.23)$ & $14.06(3.13,28.05)$ \\
\hline
\end{tabular}

Cl confidence interval
$84.3 \mathrm{~cm}$ [24], Pakistan $20.9 \mathrm{~kg} \mathrm{~m}^{-2} ; 77.7 \mathrm{~cm} \mathrm{[25]} \mathrm{and}$ Bangladesh $19.3 \mathrm{~kg} \mathrm{~m}^{-2}$ [26]; $72.8 \mathrm{~cm}$ [27]. Between 1980 and 2008, mean BMI of males worldwide increased by $0.4 \mathrm{~kg} / \mathrm{m}^{2}$ per decade [28]. Simultaneously, the mean BMI of the Sri Lankan rural and urban population has increased significantly during the past decade possibly due to nutrition transition [20]. In addition to sedentary lifestyle and poor dietary habits, negative effects of globalization, urbanization, and increasing age of the adult population likely contributed to this increasing BMI [29].

Current study revealed that the prevalence rates of overweight and obesity among men in the Central Province of Sri Lanka were 31.8 and $12.3 \%$, respectively based on the WHO cut-off values for Asians (Table 4). However, Katulanda et al. [20] reported that $25.2 \%$ of the adult Sri Lankan population were overweight, while $9.2 \%$ were obese in the year 2010, which are lower compared to the findings of the present study. Further, findings of the study conducted in 2010 by Wijewardana et al. [30], reported a prevalence rate of overweight or obesity in males in four provinces of Sri Lanka as $20.3 \%$, reflecting a trend of increasing obesity, as seen in many countries. Nevertheless, this is much lower than the prevalence rates of overweight (BMI $\geq 25.0$ $\left.\mathrm{kgm}^{-2}-66.3 \%\right)$ and obesity (BMI $\geq 30.0 \mathrm{kgm}^{-2}-32.2 \%$ ) in males in the USA in 2003/2004 [31]. Asian countries are also showing an increasing trend of overweight and obesity [32]. Asian region contains some of the most populous countries in the world (China and India), and has under gone pronounced demographic, epidemiologic, and socio economic change in recent decades. In China, the prevalence rate of overweight $\left(\geq 25.0 \mathrm{~kg} / \mathrm{m}^{2}\right)$ and obesity $\left(\geq 30.0 \mathrm{~kg} / \mathrm{m}^{2}\right)$ were 25.5 and $4.7 \%$ in 2008 in men respectively whereas in India they were 9.9 and $1.3 \%$ respectively in 2008 in men [5].

According to Katulanda et al. [20] female sex, living in urban environments, a high level of education, high income and being in the middle age were the risk factors for overweight and obesity in Sri Lankan adults. Present results indicate that among the variables studied, increased age, ethnicity, high family income and low physical activity level (trend) are associated with overweight and obesity. It was discovered that when the age increases by 10 years, a person is more likely to become overweight or obese. The present study further observed that, individuals aged 31-50 years had significantly higher risk for being obese than individuals less than or equal to 30 years. These results are comparable with the findings of Marengoni et al. [33], that increasing age was associated with a more than 50\% increased risk for multi-morbidity. Similar findings have also been observed by several research studies [21, 34, 35], where aging is considered as a risk factor for becoming obese. 
Table 6 Odds ratios of overweight and obesity in males - multinomial logistic regression analysis

\begin{tabular}{lll}
\hline Covariate & $\begin{array}{l}\text { Overweight } \\
\text { OR }(95 \% \mathrm{Cl})\end{array}$ & $\begin{array}{l}\text { Obesity } \\
\text { OR }(95 \% \mathrm{Cl})\end{array}$ \\
\hline Age & $1.449(1.280,1.641)$ & $1.647(1.391,1.950)$ \\
Ethnicity & $1.684(1.067,2.658)$ & $2.608(1.492,4.560)$ \\
Moor vs Sinhalese & $1.513(0.990,2.312)$ & $1.726(0.981,3.036$ \\
Tamil vs Sinhalese & & \\
Family income & $3.305(1.105,9.890)$ & $2.906(0.703,12.107)$ \\
Group 5 vs group 1 & $2.742(1.023,7.348)$ & $2.278(0.424,8.321)$ \\
Group 4 vs group 1 & $2.356(0.882,6.290)$ & $1.441(0.394,5.266)$ \\
Group 3 vs group 1 & $1.739(0.608,4.975)$ & $1.990(0.506,7.826)$ \\
Group 2 vs group 1 & $1.138(0.983,1.317)$ & $0.898(0.744,1.084)$ \\
Physical activity level & $1.302(0.965,1.788)$ & $0.836(0.564,1.238)$ \\
High vs low & $1.108(0.739,1.682)$ & $1.244(0.788,2.044)$ \\
Medium vs low & & 0.0164 \\
\hline
\end{tabular}

$n=1689$

Present data also revealed that there are ethnic differences in the prevalence rates of overweight and obesity. Moors showed higher incidences of overweight and obesity compared to Sinhalese. This may be due to the different dietary habits associated with diverse ethnic groups. Similar to the present findings, De Silva et al. also observed a higher prevalence rate of obesity in Moor community in their research conducted in Kalutara district of Sri Lanka [36]. This observation is also supported by the findings of the research carried out by Katulanda et al. [37] among Sri Lankan adults in 2012, where they have found out that Moors were more physically inactive than Tamils and Sinhalese which was associated with obesity and other chronic diseases such as cardiovascular diseases, diabetes and hypertension. Further, in 2014, Jayawardena et al. reported that Moors have a higher energy and protein intake and consume more fat rich food compared to Indian Tamils, Sri Lankan Tamils and Sinhalese [38]. However, ethnic difference was not recognized in the two large surveys conducted in Sri Lanka in years 2005 and 2006 on obesity $[20,30]$.

Jayawardena et al. [39] reported that daily intake of fruits and dairy among Sri Lankans (only 0.4 portions/ day) are well below the national recommendations (2-3 portions/day), and the dietary pattern of the present study population reflected that the consumption of fruits was indeed low. Many studies reported an inverse relationship between consumption of fruits and weight gain [40-43] while few studies reported no association between increased consumption of fruits and weight gain [44-46]. Our study did not find a significant association between fruit intake and obesity, maybe due to the low level of fruit intake in the sample. In contrast to previous cross sectional studies showing a positive association between alcohol intake and BMI [47-49], the current study showed a trend for alcohol consumption to have a negative association with overweight and obesity. Similar results were reported by several research studies [50-52]. Further, a 9 year follow up study done by Wang et al. with 19,220 women also showed that a higher alcohol intake at baseline was associated with a lower risk of becoming overweight or obese in the following years [53]. Two other cohort studies found no significant association between alcohol intake and BMI [54, 55]. In addition, two research studies have confirmed that obesity was inversely associated with drinking frequency $[56,57]$. This may due to the fact that drinkers usually substitute alcohol for other foods $[53,56,57]$ potentially leading to a negative energy balance.

Some studies suggested that number of sleeping hours have positive relationship with obesity $[19,58]$ while others suggest that less sleeping hours increase the incidences of obesity $[59,60]$. However, this study revealed that sleeping hours did not have any relationship with overweight or obesity which is reported similarly in a clinical review done by Marshall et al., where they have found out that neither long nor short sleep was associated with obesity [61].

Low levels of physical activity has been shown to be associated with increased obesity in many research studies conducted worldwide including Sri Lanka [18, 20, 62, 63]. Further, there is an inverse association of high physical activity with obesity and unhealthy weight gain [64-66]. We did find a trend for higher physical activity to associate with lower odds of being obese (odds ratio: 0.898 confidence interval: 0.744-1.084).

We found out that overweight and obesity were common among men with higher income levels. Similar to our findings, Katulanda et al. and De Silva et al. found a 
positive association between obesity and increasing income levels in Sri Lankan adults [20, 67]. India and Bangladesh similarly show an increase in obesity prevalence rates with increase in education levels and living standards $[68,69]$. This may be attributed to nutrition transition, with increased availability of food as well as money to purchase food, which will increase energy intake leading to obesity. However, this is opposite in higher income countries, where higher prevalence of obesity is seen in low socio economic strata [70, 71]. Nonetheless, a review by Monteiro et al. in 2004 stated that the burden of obesity in developing countries shifts to low socio economic groups, when the country's gross national product increases [72].

The current study has a few limitations. We collected data from people in the Central province, who presented themselves for a medical evaluation at the National Transport Medical Institute, Kandy, Sri Lanka. Since more than $90 \%$ of this sample were males, we only included data about males in this study. Further, due to limitations in human resource to conduct the survey, we had to conduct self-administered questionnaire which is less effective than interviewer administered questionnaires.

\section{Conclusion}

High prevalence of overweight and obesity in working age males is a threatening sign for Sri Lanka. Obesity in Central province is higher among high socio economic groups and in the Moor community. It is also evident that obesity prevalence represents a public health problem as it increases the economic burden and health risk factors of the community. As this population ages in the future and urbanization continues, the prevalence of overweight and obesity will likely to escalate. This will result in an aging population burdened with obesity as well as its deleterious effects such as cardiovascular disease, type 2 diabetes, hypertension and bone and joint disease. Since the prevalence rate is higher in certain ethnic groups and higher-income groups, targeted interventions for these groups may be necessary.

\section{Abbreviations}

BMI: Body mass index; Cl: Confidence interval; IPAQ: International Physical Activity Questionnaire; LKR: Sri Lankan rupees; OR: Odds ratio; SD: Standard Deviation; WC: Waist circumference; WHO: World Health Organization

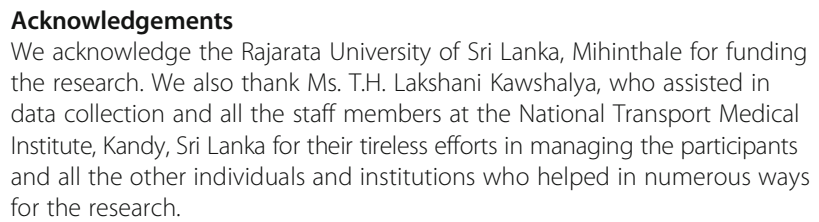

We acknowledge the Rajarata University of Sri Lanka, Mihinthale for funding the research. We also thank Ms. T.H. Lakshani Kawshalya, who assisted in data collection and all the staff members at the National Transport Medical Institute, Kandy, Sri Lanka for their tireless efforts in managing the participants and all the other individuals and institutions who helped in numerous ways for the research.

\section{Funding}

This research was funded by the Rajarata University of Sri Lanka, Mihinthale, Sri Lanka (RJT/RP \& HDC/2013/Agric./PGR/02).

\section{Availability of data and materials}

The data analyzed in this paper can be made available to researchers. Requests for access to the dataset used in this paper should be directed to the corresponding author.

\section{Authors' contributions}

WATAJ, RSJ, UR, WMTM and NSK made substantial contribution to conception and study design. SASBA and NWIAJ were involved in data collection. NWIAJ, WMTM, WATAJ, AMKRB and NSK were involved in refining the study design, statistical analysis and drafting the manuscript. WMTM, WATAJ, UR and NSK critically revised the manuscript. All authors read and approved the final manuscript.

\section{Authors' information}

NWIAJ is a lecturer at Department of Animal and Food Sciences, Faculty of Agriculture, Rajarata University of Sri Lanka; WATAJ is a Professor in the Department of Medicine, Faculty of Medicine, University of Peradeniya, Sri Lanka; WMTM is a Professor in the Department of Food Science and Technology, Faculty of Agriculture, University of Peradeniya, Sri Lanka; UR is a senior lecturer in the Department of Medicine, Faculty of Medicine, University of Peradeniya, Sri Lanka; RSJ is attached to National Transport Medical Institute, Kandy, Sri Lanka; SASBA is attached to the Department of Medicine, Faculty of Medicine, University of Peradeniya, Sri Lanka; AMKRB is a senior lecturer attached to Department of Agricultural Systems, Faculty of Agriculture, Rajarata University of Sri Lanka; NSK is a Professor in Human Nutrition in the Department of Physiology, Faculty of Medicine, University of Peradeniya, Sri Lanka.

\section{Competing interests}

The authors declare that they have no competing interests.

\section{Consent for publication}

Not applicable.

\section{Ethics approval and consent to participate}

Institutional review board approval was obtained from the ethics review committee of the Faculty of Medicine, University of Peradeniya, Sri Lanka. (2015/EC/13). All participants who enrolled in the study signed an informed consent form.

\section{Author details}

${ }^{1}$ Department of Animal and Food Sciences, Faculty of Agriculture, Rajarata University of Sri Lanka, Anuradhapura, Sri Lanka. ${ }^{2}$ Department of Medicine, Faculty of Medicine, University of Peradeniya, Peradeniya, Sri Lanka. ${ }^{3}$ Department of Food Science and Technology, Faculty of Agriculture, University of Peradeniya, Peradeniya, Sri Lanka. ${ }^{4}$ National Transport Medical Institute, Kandy, Sri Lanka. ${ }^{5}$ Department of Agricultural Systems, Faculty of Agriculture, Rajarata University of Sri Lanka, Anuradhapura, Sri Lanka.

${ }^{6}$ Department of Physiology, Faculty of Medicine, University of Peradeniya, Peradeniya, Sri Lanka.

Received: 28 June 2016 Accepted: 20 December 2016 Published online: 05 January 2017

\section{References}

1. NCD Risk Factor Collaboration (NCD-RisC). Trends in adult body-mass index in 200 countries from 1975 to 2014: a pooled analysis of 1698 populationbased measurement studies with $19 \cdot 2$ million participants. Lancet. 2016; 387(10026):1377-96.

2. Müller $\mathrm{O}$, Krawinkel M. Malnutrition and health in developing countries. Can Med Assoc J. 2005;173(3):279-86.

3. Ng M, Fleming T, Robinson M, Thomson B, Graetz N, Margono C, Abraham JP. Global, regional, and national prevalence of overweight and obesity in children and adults during 1980-2013: a systematic analysis for the Global Burden of Disease Study 2013. Lancet. 2014;384(9945):766-81.

4. Jayawardena R, Ranasinghe P, Wijayabandara M, Hills AP, Misra A. Nutrition transition and obesity among teenagers and young adults in South Asia. Curr Diabetes Rev. 2016. [Epub ahead of print].

5. World Health Organization. Non communicable diseases country profiles 2011. Geneva: World Health Organization; 2011. p. 176. 
6. Alberti KGMM, Eckel RH, Grundy SM, Zimmet PZ, Cleeman Jl, Donato KA Fruchart JC, James WPT, Loria CM, Smith SC. Harmonizing the Metabolic Syndrome A Joint Interim Statement of the International Diabetes Federation Task Force on Epidemiology and Prevention; National Heart, Lung, and Blood Institute; American Heart Association; World Heart Federation; International Atherosclerosis Society; and International Association for the Study of Obesity. Circulation. 2009;120(16):1640-5.

7. Miranda JJ, Kinra S, Casas JP, Davey SG, Ebrahim S. Non-communicable diseases in low- and middle-income countries: context, determinants and health policy. Trop Med Int Health. 2008;13(10):1225-34.

8. Dhalwani NN, Zaccardi F, O'Donovan G, Carter P, Hamer M, Yates T, Davies M Khunti K. Association Between Lifestyle Factors and the Incidence of Multimorbidity in an Older English Population. J Gerontol A Biol Sci Med Sci. 2016. [Epub ahead of print].

9. Tennakoon SU, Kumar BN, Nugegoda DB, Meyer HE. Comparison of cardiovascular risk factors between Sri Lankans living in Kandy and Oslo. BMC Public Health. 2010;10(1):654.

10. World Health Organization. Physical status: the use and interpretation of anthropometry. Report of a WHO Expert Committee. World Health Organ Tech Rep Ser. 1995;854:424-38. World Health Organization: Geneva.

11. Bassett J, W. H. Organization. The Asia-Pacific perspective: redefining obesity and its treatment, Health Communications Australia. 2000.

12. Koh JH, Koh SB, Lee MY, et al. Optimal waist circumference cutoff values for metabolic syndrome diagnostic criteria in a Korean rural population. J Korean Med Sci. 2010;25:734-7.

13. Craig $C L$, Marshall AL, Sjöström M, Bauman AE, Booth ML, Ainsworth BE, Pratt M, Ekelund U, Yngve A, Sallis JF, Oja P. International physical activity questionnaire: 12-country reliability and validity. Med Sci Sports Exerc. 2003;35:1381-95.

14. World Health Organization. Global recommendations on physical activity for health. 2010

15. 2008 Physical Activity Guidelines for Americans. U.S. Department of Health and Human Services. Available at: http://health.gov/paguidelines/. Cited on 16 Feb 2015.

16. Katulanda P, Ranasinghe $P$, Jayawardena R, Constantine GR, Rezvi Sheriff MH, Matthews DR. The prevalence, predictors and associations of hypertension in Sri Lanka: a cross-sectional population based national survey. Clin Exp Hypertens. 2014;36(7):484-91.

17. Katulanda P, Ranasinghe P, Jayawardana R, Sheriff R, Matthews DR. Metabolic syndrome among Sri Lankan adults: prevalence, patterns and correlates. Diabetol Metab Syndr. 2012;4(1):1.

18. Ko G, Chan J, et al. Association between sleeping hours, working hours and obesity in Hong Kong Chinese: the 'better health for better Hong Kong'health promotion campaign. Int J Obes. 2007;31(2):254-60.

19. Agresti A. An introduction to categorical data analysis. 2nd ed. New York: Wiley; 2007

20. Katulanda P, Jayawardena MAR, Sheriff MHR, Constantine GR, Matthews DR. Prevalence of overweight and obesity in Sri Lankan adults. Obes Rev. 2010;11(11):751-6.

21. Deepa M, Farooq S, Deepa R, Manjula D, Mohan V. Prevalence and significance of generalized and central body obesity in an urban Asian Indian population in Chennai, India (CURES: 47). Eur J Clin Nutr. 2009;63(2):259-67.

22. Misra A, Vikram NK, Gupta R, Pandey RM, Wasir JS, Gupta VP. Waist circumference cutoff points and action levels for Asian Indians for identification of abdominal obesity. Int J Obes. 2006:30(1):106-11.

23. Jee SH, Sull JW, Park J, Lee SY, Ohrr H, Guallar E, Samet JM. Body-mass index and mortality in Korean men and women. N Engl J Med. 2006;355(8):779-87.

24. Lee SY, Park HS, Kim DJ, Han JH, Kim SM, Cho GJ, Kim DY, Kwon HS, Kim SR, Lee CB, Oh SJ. Appropriate waist circumference cutoff points for central obesity in Korean adults. Diabetes Res Clin Pract. 2007;75(1):72-80

25. Jafar TH, Levey AS, White FM, Gul A, Jessani S, Khan AQ, Jafary FH, Schmid CH, Chaturvedi N. Ethnic differences and determinants of diabetes and central obesity among South Asians of Pakistan. Diabet Med. 2004;21:716-23.

26. Hussain A, Vaaler S, Sayeed MA, Mahtab H, Ali SK, Khan AA. Type 2 diabetes and impaired fasting blood glucose in rural Bangladesh: a population-based study. Eur J Pub Health. 2007;17(3):291-6.

27. Zaman MM, Yoshiike N, Rouf MA, Syeed MH, Khan MRH, Haque S, Mahtab $\mathrm{H}$, Tanaka $\mathrm{H}$. Cardiovascular risk factors: distribution and prevalence in a rural population of Bangladesh. J Cardiovasc Risk. 2001;8(2):103-8.

28. Finucane MM, Stevens GA, Cowan MJ, Danaei G, Lin JK, Paciorek CJ, Singh GM, Gutierrez HR, Lu Y, Bahalim AN, Farzadfar F. National, regional, and global trends in body-mass index since 1980: systematic analysis of health examination surveys and epidemiological studies with 960 country-years and $9 \cdot 1$ million participants. Lancet. 2011;377(9765):557-67.

29. Hosseinpoor AR, Bergen N, Kunst A, Harper S, Guthold R, Rekve D, et al. Socioeconomic inequalities in risk factors for non communicable diseases in low-income and middle income countries: results from the World Health Survey. BMC Public Health. 2012;12:912.

30. Wijewardene K, Mohideen MR, Mendis S, Fernando DS, Kulathilaka T, Weerasekara D, Uluwitta P. Prevalence of hypertension, diabetes and obesity: baseline findings of a population based survey in four provinces in Sri Lanka. Ceylon Med J. 2005;50(2):62-70.

31. Ogden CL, Carroll MD, Curtin LR, Mcdowell MA, Tabak CJ, Flegal KM. Prevalence of overweight and obesity in the United States, 1999-2004. JAMA. 2006;295:1549-55.

32. Yoon KH, Lee JH, Kim JW, Cho JH, Choi YH, Ko SH, Zimmet P, Son HY. Epidemic obesity and type 2 diabetes in Asia. Lancet. 2006;368(9548):1681-8.

33. Marengoni A, Winblad B, Karp A, Fratiglioni L. Prevalence of chronic diseases and multimorbidity among the elderly population in Sweden. Am J Public Health. 2008;98:1198-200.

34. Sen J, Mondal N, Dutta S. Factors affecting overweight and obesity amongurban adults: a cross-sectional study. Epidemiol Biostat Public Health. 2013;10(1):e8741-1-11

35. Lee $S A$, Wen W, Xu WH, Zheng W, Li H, Yang G, Xiang YB, Shu XO. Prevalence of obesity and correlations with lifestyle and dietary factors in Chinese men. Obesity (Silver Spring). 2008;16:1440-7.

36. De Silva AP, De Silva SHP, Liyanage IK, Rajapakse LC, Jayasinghe KSA, Katulanda $P$, et al. Social, cultural and economical determinants of diabetes mellitus in Kalutara district, Sri Lanka: a cross sectional descriptive study. Int J Equity Health. 2012;11:76.

37. Katulanda P, Jayawardana R, Ranasinghe P, Sheriff MR, Matthews DR. Physical activity patterns and correlates among adults from a developing country: the Sri Lanka Diabetes and Cardiovascular Study. Public Health Nutr. 2013;16(09):1684-92.

38. Jayawardena R, Thennakoon S, Byrne N, Soares M, Katulanda P, Hills A. Energy and nutrient intakes among Sri Lankan adults. Int Arch Med. 2014;7(1):1.

39. Jayawardena R, Byrne NM, Soares MJ, Katulanda P, Hills AP. Food consumption of Sri Lankan adults: an appraisal of serving characteristics. Public Health Nutr. 2013;16(04):653-8.

40. Lin BH, Morrison RM. Higher fruit consumption linked with lower body mass index. Food Rev. 2002;25(3):28-32.

41. Singh RB, Rastogi SS, Niaz MA, Ghosh S, Singh R, Gupta S. Effect of fatmodified and fruit-and vegetable-enriched diets on blood lipids in the Indian Diet Heart Study. Am J Cardiol. 1992;70(9):869-74.

42. Stamler J, Dolecek TA. Relation of food and nutrient intakes to body mass in the special intervention and usual care groups in the Multiple Risk Factor Intervention Trial. Am J Clin Nutr. 1997;65(1):366S-73S.

43. Bes-Rastrollo M, Martínez-González MÁ, Sánchez-Villegas A, de la Fuente Arrillaga C, Martínez JA. Association of fiber intake and fruit/vegetable consumption with weight gain in a Mediterranean population. Nutrition. 2006;22(5):504-11.

44. Smith-Warner SA, Elmer PJ, Tharp TM, Fosdick L, Randall B, Gross M, Wood J, Potter JD. Increasing vegetable and fruit intake: randomized intervention and monitoring in an at-risk population. Cancer Epidemiol Biomark Prev. 2000;9(3):307-17.

45. Zino S, Skeaff M, Williams S, Mann J. Randomised controlled trial of effect of fruit and vegetable consumption on plasma concentrations of lipids and antioxidants. BMJ. 1997;314(7097):1787.

46. Serdula MK, Byers T, Mokdad AH, Simoes E, Mendlein JM, Coates RJ. The association between fruit and vegetable intake and chronic disease risk factors. Epidemiology. 1996;7(2):161-5.

47. Lahti-Koski M, Pietinen P, Heliovaara M, Vartiainen E. Associations of body mass index and obesity with physical activity, food choices, alcohol intake, and smoking in the 1982-1997 FINRISK Studies. Am J Clin Nutr. 2002;75(5):809-17.

48. Fisher M, Gordon T. The relation of drinking and smoking habits to diet: the Lipid Research Clinics Prevalence Study. Am J Clin Nutr. 1985;41(3):623-30.

49. Wannamethee SG, Shaper AG, Whincup PH. Alcohol and adiposity: effects of quantity and type of drink and time relation with meals. Int J Obes. 2005;29(12):1436-44.

50. Liu S, Serdula MK, Williamson DF, Mokdad AH, Byers T. A Prospective Study of Alcohol Intake and Change in Body Weight among US Adults. Am J Epidemiol. 1994;140(10):912-20. 
51. Gruchow HW, Sobocinski KA, Barboriak JJ, Scheller JG. Alcohol consumption, nutrient intake and relative body weight among US adults. Am J Clin Nutr. 1985;42(2):289-95.

52. Wannamethee SG, Field AE, Colditz GA, Rimm EB. Alcohol Intake and 8-Year Weight Gain in Women: A Prospective Study. Obes Res. 2004;12(9):1386-96.

53. Wang L, Lee IM, Manson JE, Buring JE, Sesso HD. Alcohol consumption, weight gain, and risk of becoming overweight in middle-aged and older women. Arch Intern Med. 2010;170(5):453-61.

54. Sherwood NE, Jeffery RW, French SA, Hannan PJ, Murray DM. Predictors of weight gain in the Pound of Prevention study. Int I Obes Relat Metab Disord. 2000;24(4):395-403.

55. French SA, Jeffery RW, Forster JL, McGovern PG, Kelder SH, Baxter JE. Predictors of weight change over two years among a population of working adults: the Healthy Worker Project. Int J Obes Relat Metab Disord. 1994;18(3):145-54.

56. Tolstrup JS, Heitmann BL, Tjønneland AM, Overvad OK, Sørensen TI, Grønbaek MN. The relation between drinking pattern and body mass index and waist and hip circumference. Int J Obes. 2005;29(5):490-7.

57. Breslow RA, Smothers BA. Drinking patterns and body mass index in never smokers national health interview survey, 1997-2001. Am J Epidemiol. 2005;161(4):368-76.

58. Santos AC, Ebrahim S, Barros H. Alcohol intake, smoking, sleeping hours, physical activity and the metabolic syndrome. Prev Med. 2007;44(4):328-34.

59. Gangwisch JE, Malaspina D, Boden-Albala B, et al. Inadequate sleep as a risk factor for obesity: analyses of the NHANES I. Sleep. 2005;28(10):1289-96.

60. Chaput JP, Brunet M, Tremblay A. Relationship between short sleeping hours and childhood overweight/obesity: results from the 'Quebec en Forme' Project. Int J Obes. 2007;30(7):1080-5.

61. Marshall NS, Glozier N, Grunstein RR. Is sleep duration related to obesity? A critical review of the epidemiological evidence. Sleep Med Rev. 2008; 12(4):289-98.

62. Zhang X, Sun Z, Zheng L, Liu S, Xu C, Li J, Zhao F, Hu D, Sun Y. Prevalence and associated factors of overweight and obesity in a Chinese rural population. Obesity (Silver Spring). 2008;16:168-71.

63. Hajian-Tilaki KO, Heidari B. Prevalence of obesity, central obesity and the associated factors in urban population aged 20-70 years, in the north of Iran: a population-based study and regression approach. Obes Rev. 2007;8:3-10.

64. Kwon S, Wang M, Hawkins M. Association between self-reported physical activity and obesity among White, Black, Hispanic, and Asian Americans: 2007 and 2009 brfss. Ethn Dis. 2016;23(2):129-35.

65. Fogelholm M, Kukkonen-Harjula K. Does physical activity prevent weight gain-a systematic review. Obes Rev. 2000;1(2):95-111.

66. Erlichman J, Kerbey AL, James WP. Physical activity and its impact on health outcomes. Paper 2: Prevention of unhealthy weight gain and obesity by physical activity: an analysis of the evidence. Obes Rev. 2002;3(4):273-87.

67. De Silva AP, De Silva SH, Haniffa R, Liyanage IK, Jayasinghe KS, Katulanda P, Wijeratne CN, Wijeratne S, Rajapakse LC. A cross sectional survey on social, cultural and economic determinants of obesity in a low middle income setting. Int J Equity Health. 2015;14(1):1-9.

68. Subramanian SV, Kawachi I, Smith GD. Income inequality and the double burden of under- and overnutrition in India. J Epidemiol Community Health. 2007;61:802-9.

69. Razzaque A, Nahar L, Van Minh H, Ng N, Juvekar S, Ashraf A, et al. Social factors and overweight: Evidence from nine Asian INDEPTH Network sites. Glob Health Action. 2009;2:54-9.

70. McLaren L. Socioeconomic Status and Obesity. Epidemiol Rev. 2007;29:29-48.

71. Rennie KL, Jebb SA. Prevalence of obesity in Great Britain. Obes Rev. 2005;6:11-2.

72. Monteiro CA, Moura EC, Conde WL, Popkin BM. Socioeconomic status and obesity in adult populations of developing countries: a review. Bull World Health Organ. 2004;82(12):940-6.

\section{Submit your next manuscript to BioMed Central and we will help you at every step:}

- We accept pre-submission inquiries

- Our selector tool helps you to find the most relevant journal

- We provide round the clock customer support

- Convenient online submission

- Thorough peer review

- Inclusion in PubMed and all major indexing services

- Maximum visibility for your research

Submit your manuscript at www.biomedcentral.com/submit
Biomed Central 